Article

\title{
Effect of C Addition on as-Cast Microstructures of High Nb Containing TiAl Alloys
}

\author{
Jinhu Liu ${ }^{1}$, Fuqiang Zhang ${ }^{2}$, Hai Nan ${ }^{1,3,4}$, Xin Feng ${ }^{1,3,4}$ and Xianfei Ding 1,3,4,* \\ 1 Cast Titanium Alloy R\&D Center, Beijing Institute of Aeronautical Materials, Beijing 100095, China; \\ Jinhumail@163.com (J.L.); nanhai531@yahoo.com (H.N.); xfeng12b@alum.imr.ac.cn (X.F.) \\ 2 State Key Laboratory for Advanced Metals and Materials, University of Science and Technology Beijing, \\ Beijing 100083, China; zhangfq11@126.com \\ 3 Beijing Engineering Research Center of Advanced Titanium Alloy Precision Forming Technology, \\ Beijing Institute of Aeronautical Materials, Beijing 100095, China \\ 4 BAIMTEC Material Co., Ltd., Beijing 100094, China \\ * Correspondence: xianfeimail@gmail.com; Tel.: +86-10-6249-7564
}

Received: 10 October 2019; Accepted: 5 November 2019; Published: 7 November 2019

\begin{abstract}
Two high Nb-containing TiAl alloys, Ti46.6Al7.5Nb0.5Si0.2B (Alloy A) and Ti46.1 Al7.4Nb5C0.5Si0.2B (Alloy B), were prepared by graphite mold casting. As-cast microstructures of the two alloys were characterized to clarify the effect of carbon addition. The results show that 5 at. $\%$ carbon addition can change the primary solidification phase from $\beta$ phase to $\alpha$ phase. The as-cast microstructure of Alloy A consists of a fully $\alpha_{2}+\gamma$ lamellar structure and interdendritic eutectic silicide with a volume fraction of $2.3 \%$. However, in Alloy B, the lamellar structure only forms in the dendritic stem and the massive $\gamma$ is observed in the interdendritic regions. Two types of carbides, $\mathrm{Ti}_{2} \mathrm{AlC}$ and $\mathrm{TiC}$, are produced in Alloy $\mathrm{B}$. A large number of randomly distributed primary $\mathrm{Ti}_{2} \mathrm{AlC}$ particles with volume fraction of $14.9 \%$ are observed in both the dendritic and interdendritic regions. Irregularly shaped $\mathrm{TiC}$ remains inside of the large $\mathrm{Ti}_{2} \mathrm{AlC}$ particle, suggesting $\mathrm{TiC}$ carbides transformed to $\mathrm{Ti}_{2} \mathrm{AlC}$ during cooling. The addition of carbon also changes the morphology of the silicides from a eutectic structure to a blocky structure in the massive $\gamma$ matrix or at the interface of the $\mathrm{Ti}_{2} \mathrm{AlC}$ and the $\gamma$ matrix. High level of niobium greatly increases the solid solution limit of carbon, since $\mathrm{C}$ content in the matrix is much higher than the solid solubility of that in the TiAl binary system. The hardness of the matrix increases from $325 \mathrm{HV}$ to $917 \mathrm{HV}$ caused by the addition of carbon.
\end{abstract}

Keywords: TiAl alloy; carbides; microstructure; solidification; vickers hardness

\section{Introduction}

$\gamma$-TiAl alloys have gained great interest for high temperature-applications such as civil aero-engines low-pressure turbine (LPT) blades and vehicle engines turbocharger [1], because of their low density and good creep properties as well as their excellent oxidation resistance up to $750{ }^{\circ} \mathrm{C}$ [2]. However, their insufficient high-temperature properties limit their applications towards higher temperatures [3-6]. It has been found that high $\mathrm{Nb}$ content is able to increase the high temperature performance of the conventional TiAl alloy, such as high-temperature oxidation resistance [7], creep resistance, and high-temperature strength $[8,9]$.

Recent studies have shown that alloying with light elements such as N, C, and B can achieve significant improvement of mechanical properties through the solution hardening and precipitate reinforcement effects [10-19]. These precipitates are called $\mathrm{M}_{n+1} \mathrm{AX} X_{n}$ phase (where $\mathrm{M}$ is a transition group element such as $\mathrm{Ti}, \mathrm{Cr}, \mathrm{Y}, \mathrm{Zr}, \mathrm{Nb}$, etc., $\mathrm{A}$ is a group III or IV element such as $\mathrm{Al}, \mathrm{Si}$, etc., $\mathrm{X}$ is $\mathrm{C}, \mathrm{N}$, etc., $n=1,2,3$ ), which can induce to excellent properties include high temperature 
resistance and excellent self-lubricating properties. $M_{n+1} \mathrm{AX}$ n phase is considered to be a highly promising particle-reinforced phase of $\gamma$-TiAl alloys [20,21]. Carbon addition could form carbides with $\mathrm{M}_{n+1} \mathrm{AX}_{n}$ phase structure. However, as an interstitial element, carbon will greatly change the solute segregation, even the solidification path of $\gamma$-TiAl alloys, leading to a major hindrance to control the solidification microstructures.

In recent years, many studies have been reported on the precipitated carbides in $\gamma$-TiAl alloys and the influences of carbon addition on the as-cast microstructures. Previous studies showed that the carbides precipitated in the $\mathrm{TiAl}$ alloy are mainly $\mathrm{TiC}, \mathrm{Ti}_{2} \mathrm{AlC}$, $\mathrm{Ti}_{3} \mathrm{AlC}$, etc. [4]. $\mathrm{TiC}$ starts to appear at the early stage of solidification due to the highest melting point, while $\mathrm{Ti}_{2} \mathrm{AlC}$ and $\mathrm{Ti}_{3} \mathrm{AlC}$ are produced depending on the alloy chemical and cooling conditions in the subsequent solidification process. Witusiewicz et al. [22] reported that, in the ternary system Ti-Al-C, under equilibrium solidification conditions, the $\mathrm{H}$ phase $\left(\mathrm{Ti}_{2} \mathrm{AlC}\right)$ starts to precipitate at $1689^{\circ} \mathrm{C}$, and the $\mathrm{P}$ phase $\left(\mathrm{Ti}_{3} \mathrm{AlC}\right)$ starts to precipitate at $1630^{\circ} \mathrm{C}$. The $\mathrm{P}$ phase is a metastable phase, which will decompose during solidification, and re-precipitate after the subsequent heat treatment. Wang et al. [23] found that the increase in the amount of P-type carbides is positively correlated with the carbon content, while the increase in carbon content also increases the thermal stability of P-type carbides. Lapin et al. [4] reported that in-situ composite consists of $\mathrm{TiAl}$ matrix and $\mathrm{TiC}_{1-X}$ with coarse $\mathrm{Ti}_{2} \mathrm{AlC}$ and fine secondary $\mathrm{Ti}_{2} \mathrm{AlC}$ (H-phase) and $\mathrm{Ti}_{3} \mathrm{AlC}$ (P-phase) which contribute to the compressive strength. Schwaighofer et al. [15] reported that adding $0 \sim 1$ at. $\%$ carbon to the TNM alloy change the solidification path from $\beta$-solidified $L \rightarrow L+$ $\beta \rightarrow \beta \rightarrow \beta+\alpha$ to peritectic transformation $L \rightarrow L+\beta \rightarrow L+\beta+\alpha \rightarrow \beta+\alpha$. In the recent studies on the in-situ carbide precipitation strengthening of high $\mathrm{Nb}$ containing TiAl alloys, the carbon content was mostly concentrated in the range of $0 \sim 0.75$ at. $\%$. Only a small amount of P-type and H-type carbides and no TiC carbide were observed in the reported alloys in this range. Moreover, most of the studies were concentrated on the Ti-Al-Nb ternary alloys. It is still unclear what roles the carbon addition to the phase constituent and morphology play in other commonly used high $\mathrm{Nb}$-containing TiAl alloys with the alloying elements, such as boron and silicon.

In this work, 5 at. $\%$ carbon is added to high $\mathrm{Nb}$-containing TiAl alloys to clarify the effect of carbon addition on the as-cast microstructures. The morphology and distribution changes of the borides, silicides, and matrix caused by carbon addition will be characterized. The solidification path and the precipitate behaviors of the carbides and other phases will also be discussed.

\section{Experimental Procedures}

Two cast ingots with a diameter of $45 \mathrm{~mm}$ and length of $150 \mathrm{~mm}$ were prepared by graphite mold casting. The ingots had the nominal compositions of Ti-45Al-8Nb-0.5Si-0.2B- $x \mathrm{C}(x=0,5)(\mathrm{at} . \%)$. Master ingots were prepared by using pure Ti bar (99.96 wt.\%), pure Al (99.99 wt.\%), pure Si powders (99.99 wt.\%), TiC powders (99.99 wt.\%), AlTiB alloys (B: 0.01 wt.\%), and AlNb alloys (Nb: 75.41 wt.\%). Melting of the ingots was performed in a vacuum induction furnace (Jinzhou Dianlu Technology Co.,Ltd.,China) under argon atmosphere and each ingot was remelted twice to ensure uniformity. The chemical compositions which were determined by the chemical method of two experimental alloys, Alloy A and B, are listed in Table 1, in which the light element carbon is detected by the pulse heating infrared thermal conductivity method.

Table 1. Chemical composition of experimental alloys in at.\%.

\begin{tabular}{ccccccc}
\hline Alloy & Ti & Al & Nb & Si & B & C \\
\hline A (Ti45Al8Nb0.5Si0.2B) & Bal. & 46.6 & 7.5 & 0.5 & 0.2 & - \\
B (Ti45Al8Nb5C 0.5Si0.2B) & Bal. & 46.1 & 7.4 & 0.5 & 0.2 & 4.6 \\
\hline
\end{tabular}

For as-cast microstructure observation, a bar was sectioned from each of the ingots in the middle of the radius in the cross-section, and then cut longitudinally into two at half-length of the bar. The metallographic specimens were prepared by standard grinding on abrasive papers with 
various grain sizes of up to $10 \mu \mathrm{m}$ and polishing on diamond pastes with 1.5 and $0.5 \mu \mathrm{m}$ grain sizes. Microstructures were analyzed by field-emission scanning electron microscopy (FE-SEM) equipped with an energy/wavelength-dispersive spectrometer (EDS/WDS), using a Zeiss SUPRA 55 (Carl Zeiss AG, Oberkochen, Germany) in backscattered electron (BSE) and scanning electron (SE) imaging modes. The matrix and precipitates were quantitatively analyzed by an electron probe micro-analyzer (EPMA) (JXA-8100, JEOL, Tokyo, Japan). The phase constituent was analyzed by using X-ray diffraction (XRD) technique. Measurement was carried out with a Bruker D8 Advance X-ray diffractometer (Bruker, Mannheim, Germany) at room temperature, using $\mathrm{Cu}$ Ka radiation. Vickers microhardness measurements were performed on as-cast samples using a Qness $\mathrm{GmbH}$ machine (Q10A+, Qness $\mathrm{GmbH}$, Reitbauernweg, Austria) at room temperature with an applied load of $50 \mathrm{~N}$ and holding time of $2 \mathrm{~s}$.

\section{Results}

Figure 1 shows the XRD patterns of the two alloys. As shown in Figure 1, Alloy A consists of $\gamma$-TiAl phase and $\alpha_{2}-\mathrm{Ti}_{3} \mathrm{Al}$ phase, accompanied by a small amount of niobium silicon compound and B2 phase, while alloy B is mainly composed of $\gamma$-TiAl phase, little $\alpha_{2}$ phase, and a large number of carbides appear at the same time. It is shown that two types of carbides, $\mathrm{Ti}_{2} \mathrm{AlC}$ and $\mathrm{TiC}$, can be produced in Alloy B with 4.6 at.\% carbon addition.

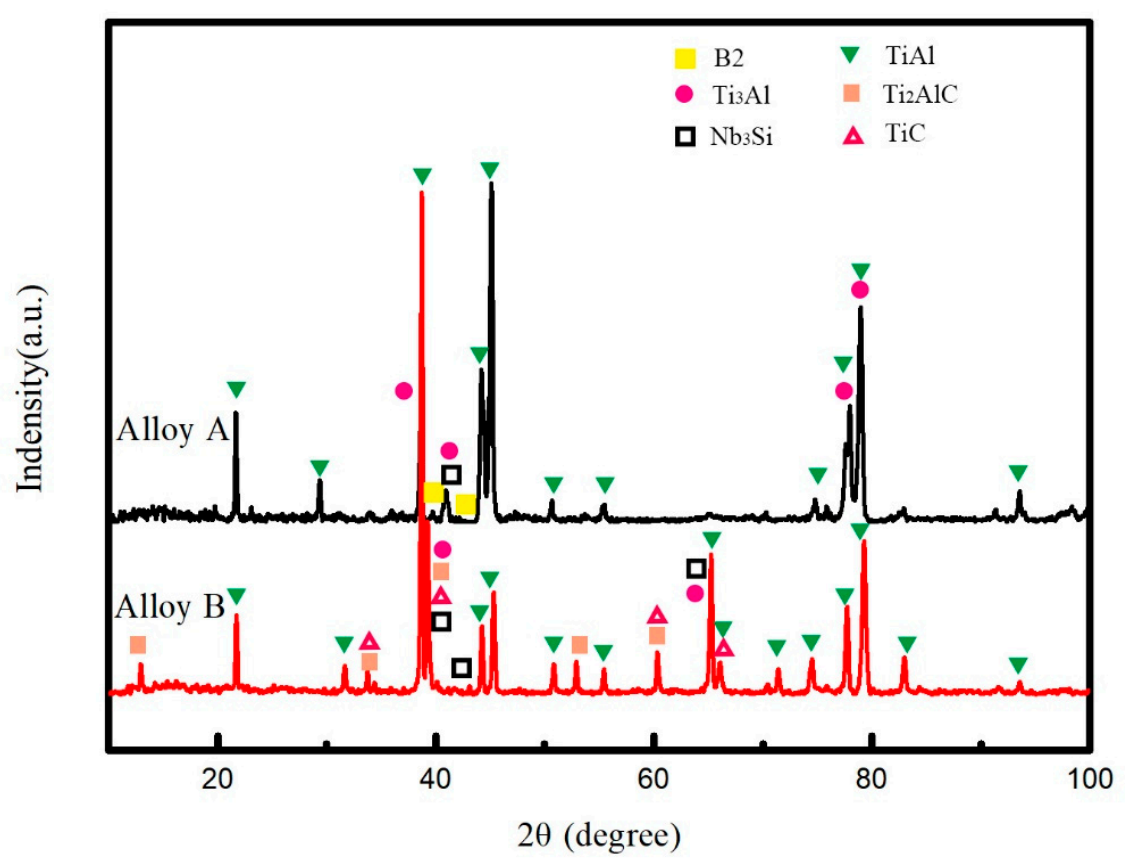

Figure 1. X-ray diffraction (XRD) patterns of the two alloys, showing the phase constituent differences for carbon addition.

BSE as-cast microstructures of Alloy A are presented in Figure 2. As shown in Figure 2a, the as-cast microstructure of Alloy A consists of refined equiaxed dendrites with a diameter of about 100-200 $\mu \mathrm{m}$ and $\mathrm{Al}$-segregation in the interdendritic regions. As shown in Figure $2 \mathrm{~b}$, there is some net $\beta$-segregation in bright grey contrast formed inside of the whole dendritic region. It is suggested that Alloy A belongs to the typical $\beta$ solidification alloy $[8,24,25]$. A fully lamellar (FL) structure with a lamellar spacing of about $1.4 \mu \mathrm{m}$ and a small fraction of B2 particles in length of $5 \mu \mathrm{m}$ can be produced in the $\beta$-segregation regions. As presented in Figure 2c, the B2 particles can be formed in either the lamella or the boundary of the lamellar colonies. A slender, slightly curved boride and a fine eutectic silicide with fish-bone morphology can be observed in the interdendritic regions of Alloy A, as illustrated in Figure 2d. The 
boride and silicide are all in small fraction and interconnected with each other. EDS compositions of the matrix are summarized in Table 2.


Figure 2. Backscattered electron (BSE) image of as-cast microstructures of Alloy A, showing (a) the refined equiaxed dendrite, (b) the fully lamellar structure in the matrix and B2 particles formed in the $\beta$-segregation region, whereas the images in the insets show the B2 particles inside of lamellar structure, (c) typical lamellar structure and B2 particles precipitation locations and (d) the slender slightly curved boride and fine eutectic silicide in the interdendritic region.

WDS analysis results show that the typical composition of the net $\beta$-segregation is Ti46.8Al7.4Nb0.8Si, while that of the surrounding lamellar structure is Ti48.4Al6.1Nb0.4Si. It can be deduced that $\mathrm{Nb}$ concentration and $\mathrm{Al}$ depletion in $\beta$-segregation region induce the $\mathrm{B} 2$ phase formation in the lamellar structure. As shown in Figure 2c, d, eutectic silicide and boride have a lower melting point, which results in coarse precipitates in the interdendritic regions. The B2 precipitation and the eutectic silicide $\mathrm{Nb}_{3} \mathrm{Si}$ particles can also be confirmed by the XRD results in Figure 1.

Figure 3 shows BSE/SE as-cast microstructures of Alloy B. As shown in Figure 3a,b, the as-cast microstructures of the alloy B consists of lamellar structure in the fine cellular dendrite region with a size of approximately $100 \mu \mathrm{m}$ in diameter and massive $\gamma$ phase in the interdendritic region. There is no white $\beta$-segregation inside the primary dendrite in BSE as-cast microstructure, suggesting that not $\beta$ but $\alpha$ phase is the primary solidification phase. As shown in Figure $3 b$, some carbides with the bright grey contrast and the size of approximately $20 \mu \mathrm{m}$ can be observed in both the dendritic and interdendritic regions. Some white contrast precipitates are produced on the edge of the dendrite, which appear as silicides and borides. As presented in Figure 3c, three types of morphologies of the $\mathrm{Ti}_{2} \mathrm{AlC}$ carbides can be observed in the as-cast microstructures, which are rod-like, plate-like, and fragmented carbide. Figure 3d shows the $\alpha_{2}+\gamma$ lamellar structure in the interdendritic region and some fine silicide particles precipitated at the lamellar interface. The interlamellar spacing is uneven, and the lamella is sometimes uncontinuous and interrupted by the carbides or massive $\gamma$. The maximum thickness of lamella $\alpha_{2}$ or $\gamma$ is approximately $2 \mu \mathrm{m}$. As shown in Figure 3e, two different types of carbides with one encapsulating another are observed in Alloy B. The two carbides exhibit with different contrast in the BSE microstructures. The light grey one is located on the inside, and the dark grey one exists on the outside. Combined with XRD and EDS analysis, as shown in Figure 1 
and Table 2, respectively, the inside is $\mathrm{TiC}$, and the outside is $\mathrm{Ti}_{2} \mathrm{AlC}$, this composite structure of $\mathrm{TiC}$ and $\mathrm{Ti}_{2} \mathrm{AlC}$ has also been confirmed by $\mathrm{SE}$ mode image in the inset of Figure 3e. Figure $3 \mathrm{f}$ shows the granular niobium silicide with white contrast and irregular morphology formed in the massive $\gamma$ matrix or at the interface of the $\mathrm{Ti}_{2} \mathrm{AlC}$ and the $\gamma$ matrix. EDS compositions of all the other precipitates and matrix are also summarized in Table 2.


Figure 3. BSE/Secondary electron (SE) image of as-cast microstructures of Alloy B, showing (a) the fine dendrite structures with a large number of massive $\gamma$ phase in the interdendritic regions, (b) primary carbides distributed in both dendrite and interdendritic regions, (c) various morphologies of the randomly distributed carbides, (d) $\gamma-\alpha_{2}$ lamellar structure with fine silicides precipitated in the lamellar interface, (e) the $\mathrm{TiC}$ particle formed in the center of $\mathrm{Ti}_{2} \mathrm{AlC}$, whereas the image in the insets show the two particles morphologies in SE mode and (f) the granular niobium silicide precipitated in the massive $\gamma$ matrix. 
Table 2. Energy dispersive spectrometer (EDS) compositions (at.\%) of different phases and matrix in the two as-cast experimental alloys.

\begin{tabular}{|c|c|c|c|c|c|c|}
\hline \multirow{2}{*}{ Phases } & \multicolumn{6}{|c|}{ Alloy A|Alloy B } \\
\hline & $\mathrm{Ti}$ & Al & $\mathrm{Nb}$ & $\mathrm{Si}$ & B & $\mathrm{C}$ \\
\hline Lamellar $\gamma$ & $45.1 \pm 0.5 \mid 37.2 \pm 0.2$ & $48.4 \pm 0.3 \mid 54.7 \pm 0.3$ & $6.1 \pm 0.2 \mid 5.6 \pm 0.1$ & $0.4 \pm 0.1 \mid 0.4 \pm 0.1$ & $0.2 \pm 0.1 \mid 0.2 \pm 0.1$ & $-\mid 2.0 \pm 0.2$ \\
\hline Lamellar $\alpha_{2}$ & $50.5 \pm 0.6 \mid 39.5 \pm 0.2$ & $43.3 \pm 0.3 \mid 50.2 \pm 0.5$ & $5.9 \pm 0.1 \mid 6.9 \pm 0.2$ & $0.42 \pm 0.1 \mid 0.3 \pm 0.1$ & $0.1 \pm 0.1 \mid 0.1 \pm 0.1$ & $-\mid 3.0 \pm 0.1$ \\
\hline Massive $\gamma$ & $-\mid 32.6 \pm 0.3$ & $-\mid 59.2 \pm 0.6$ & $-\mid 5.8 \pm 0.8$ & $-\mid 0.3 \pm 0.1$ & $-\mid 0.1 \pm 0.1$ & $-\mid 2.0 \pm 0.2$ \\
\hline B2 particle & $51.4 \pm 0.8 \mid-$ & $38.6 \pm 0.4 \mid-$ & $9.8 \pm 0.7 \mid-$ & $0.1 \pm 0.1 \mid-$ & $0.1 \pm 0.1 \mid-$ & $-\mid-$ \\
\hline $\mathrm{Ti}_{2} \mathrm{AlC}$ & $\backslash / 42 \pm 1.3$ & $\backslash \mid 26.4 \pm 0.9$ & $\backslash \mid 7.2 \pm 0.3$ & $\backslash \mid 0.2 \pm 0.1$ & $\backslash \mid 0.1 \pm 0.1$ & $\backslash \mid 24.2 \pm 1.1$ \\
\hline $\mathrm{TiC}$ & $\backslash \mid 42.1 \pm 0.7$ & $\backslash \mid 10.6 \pm 0.5$ & $\backslash 6.6 \pm 0.2$ & $\backslash 0.2 \pm 0.1$ & $\backslash 0.1 \pm 0.1$ & $\backslash 40.6 \pm 1.8$ \\
\hline $\mathrm{Nb}_{3} \mathrm{Si}$ & $48.0 \pm 0.2 \mid 44.11 \pm 0.2$ & $24.4 \pm 0.2 \mid 42.3 \pm 0.2$ & $8.0 \pm 0.2 \mid 10.4 \pm 0.1$ & $19.5 \pm 0.2 \mid 3.23 \pm 0.1$ & $0.1 \pm 0.1 \mid 0.1 \pm 0.1$ & $\backslash \mid 2.7 \pm 0.2$ \\
\hline
\end{tabular}


Combined with the TiAlNb phase diagram, the addition of a large amount of $\mathrm{Nb}$ elements makes the $\beta$ phase region expanded compared to the TiAl binary phase diagram [26]. The solidification path of the Alloy A is $L \rightarrow L+\beta \rightarrow \beta+\alpha \rightarrow \alpha \rightarrow \alpha+\gamma \rightarrow \gamma+\alpha_{2}$ [25], but the BSE image of the carbon-containing Alloy B shows a typical peritectic reaction [24], in which solidification path is $\mathrm{L} \rightarrow \mathrm{L}+\mathrm{H}\left(\mathrm{Ti}_{2} \mathrm{AlC}\right) \rightarrow \mathrm{L}+\alpha+$ $\mathrm{H} \rightarrow \alpha+\gamma+\mathrm{H} \rightarrow \gamma+\alpha_{2}+\mathrm{H}$ [15]. Determined by quantitative metallographic static analysis, the volume fraction of dendritic stems reaches $56.3 \%$, and the volume fraction of the massive $\gamma$ phase resulted by interdendritic aluminum segregation was approximately $25.3 \%$. The volume fractions of carbides and silicides are $14.9 \%$ and $4.3 \%$, respectively. The carbide volume is lower than Lapin's work [27] which is close to $20 \mathrm{vol} \%$. From the available evidence, the possibility of this reduction is caused by the different melting method and cooling rate, and further research is needed. The morphology of the carbides is very close to the previous study [28] (containing 4.8 at $\%$ carbon, which is close to the carbon content in this study). Typical round bar and plate-shaped coarse carbides appeared in both studies. In the previous study [29], the morphology of the carbide gradually changed from a thin line to a short rod as the carbon content increased, and finally became a coarse carbide. In this experiment, a small amount of short rod-shaped carbides appeared, and a large number of coarse carbides also appeared. Carbon is a strong $\alpha$ phase stabilizing element that will significantly enlarge the $\alpha$ phase region. Therefore, the solidification path enters the $L+\alpha \rightarrow \gamma$ peritectic transition region, which is equivalent to entering the phase diagram with a higher aluminum content region. This also leads to a narrower crystallization temperature interval, which makes the dendrite smaller [30]. The average dendrite diameter of Alloy A was $105 \mu \mathrm{m}$, while that of Alloy B with carbon addition alloy was $76 \mu \mathrm{m}$, with a reduction of $27.6 \%$.

Carbon addition has a great effect on the element distribution in the high $\mathrm{Nb}$-containing TiAl alloy. It can be seen from Table 2 that the content of carbon in the $\alpha_{2}$ phase is larger than that of the solid solubility in the $\gamma$ phase. According to Klein's work [24], the carbon has the highest solubility in the $\alpha_{2}$ phase, less in the $\gamma$ phase, and almost no solubility in the $\beta$ phase. In previous studies, the solid solubility of carbon in Ti-Al binary alloys was quite low at room temperature. However, in this experiment, it was observed that the solid solubility of carbon reached $2 \sim 3$ at. $\%$, indicating $\mathrm{Nb}$ addition greatly increases the solid solubility of carbon. As shown in Table 2, the Ti contained in both of the $\gamma$ phase, and the $\alpha$ phase of Alloy A are lower than that of Alloy B, since a considerable part of $\mathrm{Ti}$ is allocated in the carbide. It is worth noting that, $7.2 \mathrm{at} . \% \mathrm{Nb}$ content was detected in the carbides, suggesting the presence of $(\mathrm{Ti}, \mathrm{Nb})-\mathrm{Al}-\mathrm{C}$ solid solution. In Alloy $\mathrm{A}$, due to the occurrence of $\mathrm{Nb}$ segregation, the $\mathrm{Nb}$ solid solubility reduction effect in the $\alpha_{2}$ phase in the carbon-free Alloy $\mathrm{A}$ was pronounced. $\mathrm{Nb}$ element tends to accumulate in the $\gamma$ phase in Alloy A, which is consistent with Gerstl's results [31], however, the Nb element in the carbon-containing Alloy B tends to be dissolved in the $\alpha_{2}$ phase.

Figure 4 shows EDS mapping analysis of the carbides in Alloy B. As shown in Figure 4, two different types of carbides with one encapsulating another are formed in Alloy B. Comparatively, the inside carbide is rich in $\mathrm{Ti}, \mathrm{C}$ and depleted in $\mathrm{Al}$, but the outside carbide is rich in $\mathrm{Ti}, \mathrm{C}$ and contains $\mathrm{Al}$ and $\mathrm{Nb}$, which also suggests the inside one is $\mathrm{TiC}$ and the outside one is $\mathrm{Ti}_{2} \mathrm{AlC}$. It can be seen that the inside $\mathrm{TiC}$ exhibits a rough edge, comparing to the smooth edge of the outside $\mathrm{Ti}_{2} \mathrm{AlC}$ particles. The edges of $\mathrm{TiC}$ are mostly irregular exhibiting obvious signs of dissolution. It can be deduced that the original bulk $\mathrm{TiC}$ will be dissolved to irregular, small pieces so as to precipitate the $\mathrm{Ti}_{2} \mathrm{AlC}$ particle. This process will continue until the residual $\mathrm{TiC}$ is completely converted into $\mathrm{Ti}_{2} \mathrm{AlC}$ in proper conditions during solidification and subsequent cooling, as can be seen from the specific morphology of the $\mathrm{Ti}_{2} \mathrm{AlC}$ carbide. Lapin et al. indicated that the earliest precipitated carbide in the liquid phase is $\mathrm{TiC}_{1-X}$, and the transformation process is $\mathrm{L}+\mathrm{TiC}_{1-X} \rightarrow \mathrm{L}+\mathrm{Ti}_{2} \mathrm{AlC}$ [4]. Therefore, the TiC carbide inside of the island-like $\mathrm{Ti}_{2} \mathrm{AlC}$ is a residual unconverted nascent carbide. 



Figure 4. EDS mapping analysis of the carbides in Alloy B, showing (a) BSE microstructures for mapping and element mapping images of (b) carbon, (c) aluminum, (d) silicon, (e) titanium and (f) niobium.

As shown in the lower right corner of Figure $4 \mathrm{a}$, some white precipitates containing $\mathrm{Nb}$ and $\mathrm{Si}$ elements can be formed neighboring the $\mathrm{Ti}_{2} \mathrm{AlC}$ particle, which should be a niobium silicon compound. Since it is formed at the interface of the matrix and the carbide, its melting point is lower than that of the primary carbides include $\mathrm{Ti}_{2} \mathrm{AlC}$ and $\mathrm{TiC}$.

The niobium silicide compound can be precipitated neighboring not only the $\mathrm{Ti}_{2} \mathrm{AlC}$ particle in carbon-containing Alloy B. Figure 5 shows EDS mapping analysis of the niobium silicide precipitates in Alloy B. In Figure 5, the niobium silicon compound exhibits a bulk solid solution morphology, which is different from that in fish-bone morphology in the carbon-free alloy A. 

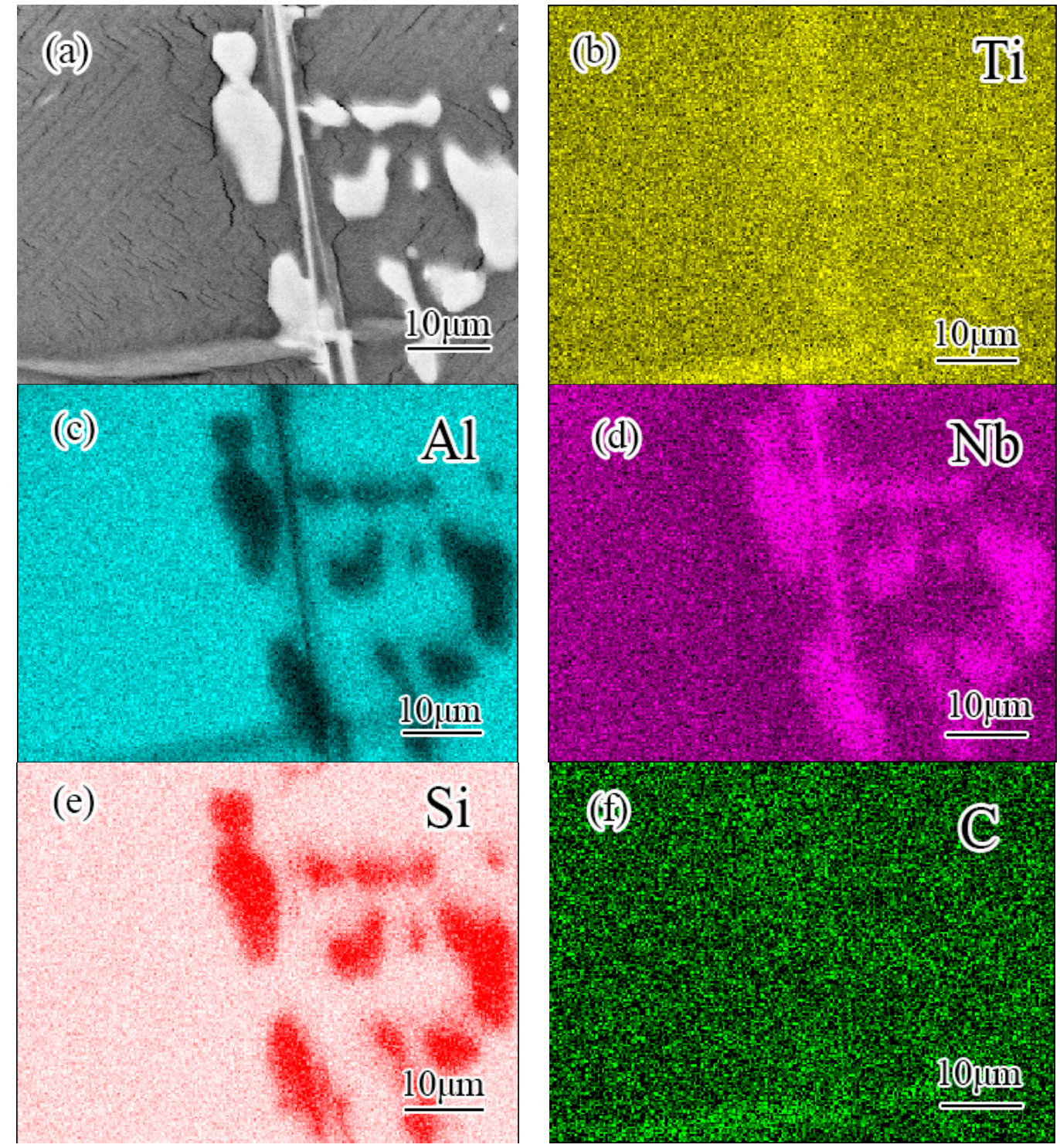

Figure 5. EDS mapping analysis of niobium silicide and boride precipitates in Alloy B, showing (a) BSE microstructure for mapping and element mapping images of (b) titanium (c) aluminum (d) niobium, (e) silicon and (f) carbon.

The morphology difference between niobium silicide compounds in the two alloys is due to the different solidification paths, owing to the addition of carbon. The primary phase of alloy $\mathrm{A}$ is The $\beta$ phase, while the primary phase of the carbon-containing alloy $B$ is the $\alpha$ phase. The partition coefficients of the Si element in the $\beta$ phase and the $\alpha$ phase are $0.5-0.8$ and $0.29-0.45$, respectively [32]. The Si element tends to be distributed in interdendritic regions at the initial stage of solidification. In the liquid phase, the partition coefficients of $\mathrm{Nb}$ element in the $\beta$ phase and the $\alpha$ phase are $1.27-1.42$ and $1.080-1.17$, respectively, and the $\mathrm{Nb}$ element tends to be distributed in the dendrites during solidification.

Furthermore, as indicated in the work of Bewlay et al. [33], there are three types of silicides in the Ti-Nb-Si ternary system. The first one is the titanium-silicon compound formed by the eutectic reaction $\mathrm{L} \rightarrow \mathrm{Ti}_{5} \mathrm{Si}_{3}+\mathrm{Ti}$ occurring at $1330{ }^{\circ} \mathrm{C}$, and the second is $\mathrm{Nb}_{3} \mathrm{Si}$ compound produced by the peritectic reaction $\mathrm{L}+\mathrm{Nb}_{5} \mathrm{Si}_{3} \rightarrow \mathrm{Nb}_{3} \mathrm{Si}$ at $1980{ }^{\circ} \mathrm{C}$, and the final one is eutectic $\mathrm{Nb}_{3} \mathrm{Si}$ formed by eutectic reaction $\mathrm{L} \rightarrow \mathrm{Nb}_{3} \mathrm{Si}+\mathrm{Nb}$ at $1880^{\circ} \mathrm{C}$. In the carbon-free alloy, the partition coefficient of $\mathrm{Nb}$ in the $\beta$ phase is large, and the content between dendrites is small. Therefore, a low-melting eutectic titanium-silicon 
compound is formed. In the carbon-containing alloy, the addition of carbon changes the solidification path, the primary phase of $\alpha$-phase, thus forming a large amount of the peritectic niobium silicon compound in the interdendritic region.

The average hardness value is shown in Table 3. The primary $\mathrm{Ti}_{2} \mathrm{AlC}$ carbide has a Vickers hardness of up to $1068 \mathrm{HV}$. The hardness of the matrix increases from $325 \mathrm{HV}$ to $917 \mathrm{HV}$ caused by the addition of carbon. Compared with the lamellar structure in carbon-free alloy, 2.8 times hardness is obtained in carbon-containing alloy, which is actually due to the carbon solid solution strengthening effect and the precipitation strengthening effect.

Table 3. Vickers hardness.

\begin{tabular}{cc}
\hline Phase and Matrix & Hv Value \\
\hline $\mathrm{Ti}_{2} \mathrm{AlC}$ carbide & $1068 \pm 8.5$ \\
Carbon-containing matrix & $917 \pm 5.7$ \\
Carbon-free matrix & $325 \pm 4.9$ \\
\hline
\end{tabular}

Klein et al. [24] has reported that both the $\alpha_{2}$ and the $\gamma$ phase significantly harden through the addition of $\mathrm{C}$. The hardness of the $\mathrm{Ti}_{2} \mathrm{AlC}$ carbide is $16.5 \%$ higher than the hardness of the matrix. It can be inferred that the carbon solid solution effect is the major strengthening factor in as-cast alloy rather than the carbide precipitation effect.

\section{Conclusions}

1. Adding 5 at.\% carbon can convert the solidification path from $L \rightarrow L+\beta \rightarrow \beta+\alpha \rightarrow \alpha \rightarrow \alpha+\gamma \rightarrow \gamma$ $+\alpha_{2}$ to $\mathrm{L} \rightarrow \mathrm{L}+\mathrm{H}\left(\mathrm{Ti}_{2} \mathrm{AlC}\right) \rightarrow \mathrm{L}+\alpha+\mathrm{H} \rightarrow \alpha+\gamma+\mathrm{H} \rightarrow \gamma+\alpha_{2}+\mathrm{H}$. The as-cast microstructure of Alloy $\mathrm{A}$ consisted of a fully $\alpha_{2}+\gamma$ lamellar structure and a dendritic internal eutectic silicide with a volume fraction of $2.3 \%$. However, in Alloy B, a lamellar structure was formed only in the dendrites, and large massive $\gamma$ was observed between the dendrites.

2. Two types of carbides, $\mathrm{Ti}_{2} \mathrm{AlC}$ and $\mathrm{TiC}$, are produced in Alloy $\mathrm{B}$. A large number of randomly distributed primary $\mathrm{Ti}_{2} \mathrm{AlC}$ particles were observed in the dendritic region with a volume fraction of $14.9 \%$. These primary carbides have a size of about $30 \mu \mathrm{m}$ and are generally rod-shaped, plate-like, or irregular in shape. The $\mathrm{TiC}$ remains in the center of the large $\mathrm{Ti}_{2} \mathrm{AlC}$, indicating the $\mathrm{TiC}$ carbide converted to $\mathrm{Ti}_{2} \mathrm{AlC}$ during cooling.

3. The addition of carbon also changes the morphology and distribution of the silicide from the coarse eutectic structure between the dendrites to the random distribution of the bulk. The high content of niobium greatly increases the solid solution limit of carbon because the $C$ content in the matrix is much higher than the solid solubility in the TiAl binary system.

4. The primary $\mathrm{Ti}_{2} \mathrm{AlC}$ carbide has a Vickers hardness of up to $1068 \mathrm{HV}$. The hardness of the matrix increased from 325 to $917 \mathrm{HV}$ due to the addition of carbon.

Author Contributions: X.D. designed and supervised the project; F.Z. synthesized the samples; J.L. performed the experiment, conducted data analysis and paper writing; X.F. reviewed and edited the manuscript. H.N. provided financial and equipment support for the experiment.

Funding: This research was funded by the National Natural Science Foundation of China, grant number 51671026, and the State Key Lab of Advanced Metals and Materials, grant number 2019-ZD05. The APC was funded by Beijing Institute of Aeronautical Materials.

Conflicts of Interest: The authors declare no conflict of interest.

\section{References}

1. Kim, Y.W.; Kim, S.L. Advances in Gammalloy Materials-Processes-Application Technology: Successes, Dilemmas, and Future. JOM 2018, 70, 553-560. [CrossRef] 
2. Clemens, H.; Mayer, S. Design, Processing, Microstructure, Properties, and Applications of Advanced Intermetallic TiAl Alloys. Adv. Eng. Mater. 2013, 15, 191-215. [CrossRef]

3. Li, M.; Xiao, S.; Chen, Y.; Xu, L.; Tian, J. The effect of carbon addition on the high-temperature properties of $\beta$ solidification TiAl alloys. J. Alloys Compd. 2018, 775, 441-448. [CrossRef]

4. Lapin, J.; Štamborská, M.; Kamyshnykova, K.; Pelachová, T.; Klimová, A.; Bajana, O. Room temperature mechanical behaviour of cast in-situ TiAl matrix composite reinforced with carbide particles. Intermetallics 2019, 105, 113-123. [CrossRef]

5. Kim, Y.W. Strength and ductility in TiAl alloy. Intermetallics 1998, 6, 623-628. [CrossRef]

6. Kim, Y.W.; Kim, S.L. Effects of microstructure and C and Si additions on elevated temperature creep and fatigue of gamma TiAl alloys. Intermetallics 2014, 53, 92-101. [CrossRef]

7. Lin, J.P.; Zhao, L.L.; Li, G.Y. Effect of $\mathrm{Nb}$ on oxidation behavior of high $\mathrm{Nb}$ containing TiAl alloys. Intermetallics 2011, 19, 131-136. [CrossRef]

8. Chen, G.L.; Xu, X.J.; Teng, Z.K.; Wang, Y.L.; Lin, J.P. Microsegregation in high Nb containing TiAl alloy ingots beyond laboratory scale. Intermetallics 2007, 15, 625-631. [CrossRef]

9. Chen, G.L.; Zhang, W.J.; Liu, Z.C.; Li, S.J. Microstructures and properties of high-Nb containing TiAl-base alloys. Gamma Titan. Alum. 1999, 1999, 371-380.

10. Perdrix, F.; Trichet, M.F.; Bonnentien, J.L.; Cornet, M.; Bigot, J. Influence of nitrogen on the microstructure and mechanical properties of Ti-48Al alloy. Intermetallics 2001, 9, 147-155. [CrossRef]

11. Karadge, M.; Gouma, P.I.; Kim, Y.W. Precipitation strengthening in K5-series $\gamma$-TiAl alloyed with silicon and carbon. Metall. Mater. Trans. A 2003, 34, 2129-2138. [CrossRef]

12. Gerling, R.; Schimansky, F.P.; Stark, A.; Bartels, A.; Kestler, H.; Cha, L.; Scheu, C.; Clemens, H. Microstructure and mechanical properties of $\mathrm{Ti} 45 \mathrm{Al} 5 \mathrm{Nb}+(0-0.5 \mathrm{C})$ sheets. Intermetallics 2008, 16, 689-697. [CrossRef]

13. Scheu, C.; Stergar, E.; Schober, M.; Cha, L.; Clemens, H.; Bartels, A.; Schimansky, F.; Cerezo, A.; Stergar, E.; Schober, M. High carbon solubility in a $\gamma$-TiAl-based Ti-45Al-5Nb-0.5C alloy and its effect on hardening. Acta Mater. 2009, 57, 1504-1511. [CrossRef]

14. Gabrisch, H.; Stark, A.; Schimansky, F.P.; Wang, L.; Schell, N. Investigation of carbides in Ti-45Al-5Nb- $x$ C alloys $(0<=x<=1)$ by; transmission electron microscopy and high energy-XRD. Intermetallics 2013, 33, 44-53.

15. Schwaighofer, E.; Rashkova, B.; Clemens, H.; Stark, A.; Mayer, S. Effect of carbon addition on solidification behavior, phase evolution and creep properties of an intermetallic $\beta$-stabilized $\gamma$-TiAl based alloy. Intermetallics 2014, 46, 173-184. [CrossRef]

16. Song, X.J.; Cui, H.Z.; Nan, H.; Na, W.; Ye, H.; Jian, T.; Qiang, S. Lamellar structure and effect of Ti 2 AlC on properties of prepared in-situ TiAl matrix composites. Ceram. Int. 2016, 42, 13586-13592. [CrossRef]

17. Song, X.; Cui, H.; Ye, H.; Nan, H.; Na, W.; Lei, D.; Qiang, S. Effect of carbon reactant on microstructures and mechanical properties of TiAl/Ti 2 AlC composites. Mater. Sci. Eng. A 2017, 684, 406-412. [CrossRef]

18. Tan, Y.; Chen, R.; Fang, H.; Liu, Y.; Ding, H.; Su, Y.; Guo, J.; Fu, H. Microstructure evolution and mechanical properties of TiAl binary alloys added with $\mathrm{SiC}$ fibers. Intermetallics 2018, 98, 69-78. [CrossRef]

19. Cui, S.; Cui, C.; Xie, J.; Liu, S.; Shi, J. Carbon fibers coated with graphene reinforced TiAl alloy composite with high strength and toughness. Sci. Rep. 2018, 8, 2364. [CrossRef]

20. Wang, Q.; Ding, H.; Zhang, H.; Chen, R.; Guo, J.; Fu, H. Variations of microstructure and tensile property of $\gamma$-TiAl alloys with 0-0. 5at\% C additives. Mater. Sci. Eng. A 2017, 700, 198-208. [CrossRef]

21. Tian, W.H.; Nemoto, M. Effect of carbon addition on the microstructures and mechanical properties of $\gamma$-TiAl alloys. Intermetallics 1997, 5, 237-244. [CrossRef]

22. Witusiewicz, V.T.; Hallstedt, B.; Bondar, A.A.; Hecht, U.; Sleptsov, S.V.; Velikanova, T.Y. Thermodynamic description of the Al-C-Ti system. J. Alloys Compd. 2015, 623, 480-496. [CrossRef]

23. Wang, L.; Gabrisch, H.; Lorenz, U.; Schimansky, F.; Schreyer, A.; Stark, A.; Pyczak, F. Nucleation and thermal stability of carbide precipitates in high $\mathrm{Nb}$ containing TiAl alloys. Intermetallics 2015, 66, 111-119. [CrossRef]

24. Klein, T.; Schachermayer, M.; Mendez-Martin, F.; Schöberl, T.; Rashkova, B.; Clemens, H.; Mayer, S. Carbon distribution in multi-phase $\gamma$-TiAl based alloys and its influence on mechanical properties and phase formation. Acta Mater. 2015, 94, 205-213. [CrossRef]

25. Imayev, R.M.; Imayev, V.M.; Oehring, M.; Appel, F. Alloy design concepts for refined gamma titanium aluminide based alloys. Intermetallics 2007, 15, 451-460. [CrossRef] 
26. Witusiewicz, V.T.; Bondar, A.A.; Hecht, U.; Velikanova, T.Y. The Al-B-Nb-Ti system: IV. Experimental study and thermodynamic re-evaluation of the binary $\mathrm{Al}-\mathrm{Nb}$ and ternary $\mathrm{Al}-\mathrm{Nb}-\mathrm{Ti}$ systems. J. Alloys Compd. 2009, 472, 133-161. [CrossRef]

27. Lapin, J.; Štamborská, M.; Pelachová, T.; Bajana, O. Fracture behaviour of cast in-situ TiAl matrix composite reinforced with carbide particles. Mater. Sci. Eng. A 2018, 721, 1-7. [CrossRef]

28. Lapin, J.; Klimová, A.; Gabalcová, Z.; Pelachová, T.; Bajana, O.; Štamborská, M. Microstructure and mechanical properties of cast in-situ TiAl matrix composites reinforced with $(\mathrm{Ti}, \mathrm{Nb})_{2} \mathrm{AlC}$ particles. Mater. Des. 2017, 133, 404-415. [CrossRef]

29. Lapin, J.; Kamyshnykova, K. Processing, microstructure and mechanical properties of in-situ Ti3Al+TiAl matrix composite reinforced with Ti2AlC particles prepared by centrifugal casting. Intermetallics 2018, 98, 34-44. [CrossRef]

30. Wu, Z.; Rui, H.; Zhang, T.; Fan, Z.; Kou, H.; Li, J. Understanding the role of carbon atoms on microstructure and phase transformation of high $\mathrm{Nb}$ containing TiAl alloys. Mater. Charact. 2017, 124, 1-7. [CrossRef]

31. Gerstl, S.S.A.; Kim, Y.W.; Seidman, D.N. Atomic Scale Chemistry of $\alpha 2 / \gamma$ Interfaces in a Multi-Component TiAl Alloy. Interface Sci. 2004, 12, 303-310. [CrossRef]

32. Daloz, D.; Hecht, U.; Zollinger, J.; Combeau, H.; Hazotte, A.; Založnik, M. Microsegregation, macrosegregation and related phase transformations in TiAl alloys. Intermetallics 2011, 19, 749-756. [CrossRef]

33. Bewlay, B.P.; Jackson, M.R.; Lipsitt, H.A. The Nb-Ti-Si ternary phase diagram: Evaluation of liquid- solid phase equilibria in Nb-and Ti-rich alloys. J. Phase Equilib. 1997, 18, 264. [CrossRef]

(C) 2019 by the authors. Licensee MDPI, Basel, Switzerland. This article is an open access article distributed under the terms and conditions of the Creative Commons Attribution (CC BY) license (http://creativecommons.org/licenses/by/4.0/). 